\title{
Analisis As-Is Pada Perencanaan Strategis Sistem Informasi Kementerian Perhubungan
}

\author{
Yudha Saintika $^{\# 1}$, Auliya Burhanuddin ${ }^{\# 2}$, Fathushahib ${ }^{\# 3}$ \\ \#1 Program Studi S1 Sistem Informasi Institut Teknologi Telkom Purwokerto \\ \#2 Program Studi S1 Informatika Institut Teknologi Telkom Purwokerto \\ \#3 Program Studi S1 Sistem Informasi Institut Teknologi Telkom Purwokerto \\ \#1 yudha@ittelkom-pwt.ac.id \\ \#2 auliya@ittelkom-pwt.ac.id \\ \#3 fathushahib@ittelkom-pwt.ac.id
}

Accepted on September 28, 2018

\begin{abstract}
Abstrak
Kementerian Perhubungan (Kemenhub) merupakan institusi dibawah pengawasan Menteri Perhubungan Berdasarkan hasil observas, Kepala Pusat Data dan Informasi (Kapusdatin) menyampaikan bahwa berbagai infrastruktur dasar berupa jaringan komputer dan pembangunan aplikasi untuk penunjang kegiatan telah dikembangkan namun dalam pengembangannya dilaksanakan secara sendiri-sendiri oleh setiap unit kerja di lingkungan Kemenhub sesuai dengan keperluan mereka sendiri, sehingga permasalahan yang terjadi adalah sistem informasi berdiri sendiri-sendiri dan sulit untuk diitegrasikan. Penelitian ini bertujuan untuk menyelesaikan salah satu domain akar permasalahan yaitu belum adanya kajian atau acuan yang memuat tentang perencanaan strategis sistem informasi khususnya untuk tahapan pendahuluan yaitu analisis As-Is yang membahas kondisi saat ini baik itu bisnis maupun SI/TI. Metode yang digunakan dalam penelitian ini yaitu ward-peppard dimana metode ini sudah umum untuk digunakan dan memuat banyak tools yang bisa dimanfaatkan. Hasil penelitian menunjukkan bahwa masih banyak permasalahan baik untuk lingkungan bisnis dan SI/TI. Berbagai permasalahan tersebut dapat menjadi input bagi proses selanjutnya yaitu perumusan strategi dan rekomendasi hingga menjadi roadmap.
\end{abstract}

Keywords: Perencanaan, As-Is, Bisnis, Strategi

\section{Pendahuluan}

Kementerian Perhubungan (Kemenhub) yang merupakan institusi dibawah pengawasan Menteri Perhubungan memiliki visi yaitu "Terwujudnya pelayanan perhubungan yang handal, berdaya saing dan memberikan nilai tambah" [1]

Berikut ini adalah arahan Menteri Perhubungan yang disampaikan dalam hasil wawancara dengan Kepala Pusat Data dan Informasi disampaikan bahwa:

1. Pengelolaan Sistem Informasi di lingkungan Kemenhub harus terintegrasi agar efisien, efektif dan bermanfaat.

2. Semua pelayanan perizinan berbasis Sistem Teknologi Informasi dan Komunikasi.

3. Pusdatin bertugas mengkonsolidasi dan mengintegrasikan seluruh infrastruktur TIK di lingkungan Kemenhub. 
4. Tahun 2015 semua Anggaran terkait TIK harus mendapatkan rekomendasi Pusdatin.

Data yang diterima oleh Pusat Data dan Infomasi (Pusdatin) terkait kegiatan pengembangan dan pembangunan sistem informasi maupun pemeliharaan dan pembangunan kegiatan Teknologi Informasi dan Komunikasi (TIK) dapat dilihat pada tabel 1.

Tabel 1 Jumlah Kegiatan TIK di lingkungan Kemenhub Telah Diolah [2]

\begin{tabular}{|c|l|c|}
\hline No. & \multicolumn{1}{|c|}{ Unit Eselon I } & $\begin{array}{c}\text { Jumlah Kegiatan Teknologi } \\
\text { Informasi dan Komunikasi } \\
\text { (TIK) Tahun 2015 }\end{array}$ \\
\hline 1 & Ditjen Perhubungan Udara & 42 Kegiatan \\
\hline 2 & Ditjen Perhubungan Laut & 5 Kegiatan \\
\hline 3 & Ditjen Perhubungan Darat & 40 Kegiatan \\
\hline 4 & Ditjen Perkeretaapian & 5 Kegiatan \\
\hline
\end{tabular}

Berdasarkan data pada tabel 1 dan didukung hasil wawancara, Kepala Pusdatin (Kapusdatin) menyampaikan bahwa berbagai infrastruktur dasar berupa jaringan komputer dan pembangunan aplikasi untuk penunjang kegiatan telah dikembangkan namun dalam pengembangannya dilaksanakan secara sendiri-sendiri oleh setiap unit kerja di lingkungan Kemenhub sesuai dengan keperluan mereka sendiri, sehingga permasalahan yang terjadi adalah sistem informasi berdiri sendiri-sendiri dan sulit untuk diitegrasikan. Masih adanya silo-silo sistem ini karena belum adanya acuan yang rinci dan rencana yang sistematis dalam pengembangan sistem informasi di Kemenhub. Permasalahan ini memberikan dampak terhadap anggaran belanja TIK di Kemenhub tidak efisien dilihat dari output yang dihasilkan belum dapat dimanfaatkan dan dirasakan hasilnya secara penuh serta tidak adanya konektivitas antar sistem yang dibangun menyebabkan kesulitan pimpinan dalam pengambilan keputusan karena membutuhkan waktu dalam pengumpulan data dan informasi yang dibutuhkan. Diagram tulang ikan (fish bone diagram) pada gambar 1 disajikan untuk melihat hubungan sebab akibat antara masalah dan akar masalah.

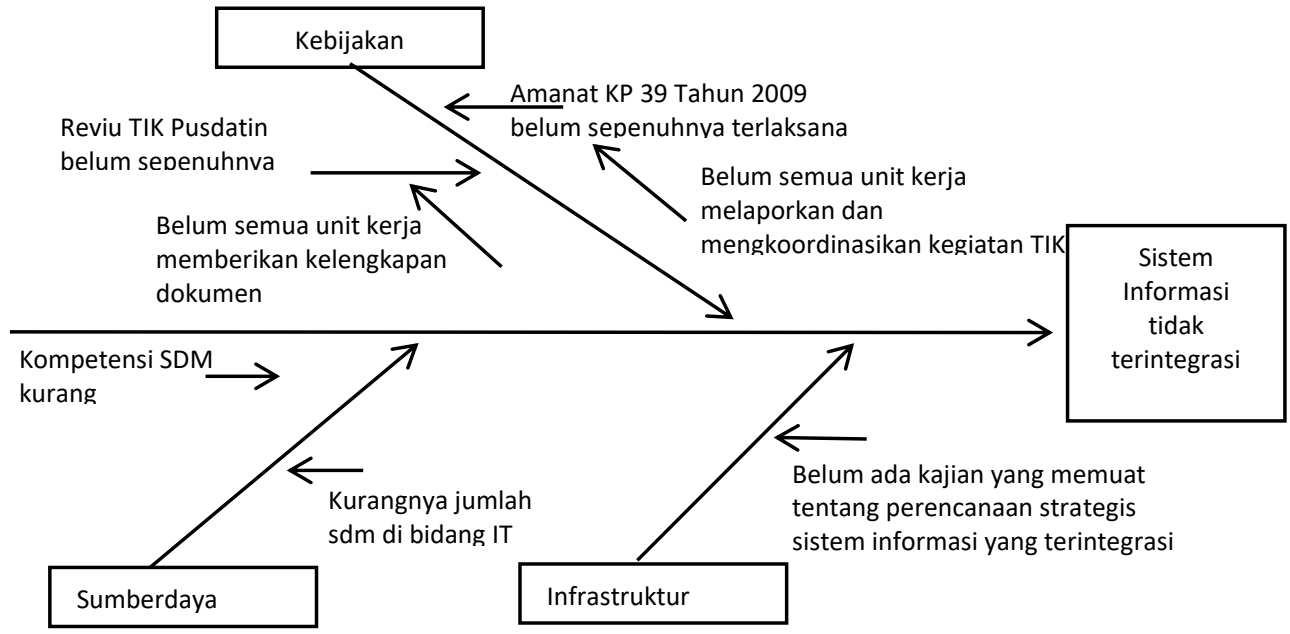

Gambar 1 Fishbone Diagram

Faktor kebijakan menjadi salah satu domain masalah yang mempengaruhi. Adapun 2 akar masalah dari faktor kebijakan adalah :

1. Amanat KP 39 Tahun 2009 belum sepenuhnya terlaksana

Akar permasalahan ini disebabkan oleh belum semua unit kerja melaporkan dan mengkoordinasikan

kegiatan TIK yang akan mereka lakukan ke Pusdatin. Hal tersebut menjadi akar permasalahan karena tidak sesuai dengan KP 39 Tahun 2009 pasal 7.

2. Reviu TIK Pusdatin belum sepenuhnya terlaksana

Akar permasalahan ini disebabkan oleh belum semua unit kerja memberikan kelengkapan dokumen yang digunakan sebagai bahan reviu Pusdatin (Kerangka Acuan Kerja dan Rencana Anggaran Biaya). 
Kemudian dari domain infrastruktur hal yang menjadi permasalahan yaitu belum adanya acuan dan rancangan sistem yang terintegrasi sehingga diperlukan kajian mendalam. Berdasarkan hasil wawancara dengan Kapusdatin menunjukkan adanya sistem informasi yang berdiri sendiri-sendiri/silo sistem yang menyebabkan harus dilakukan akses ke setiap aplikasi untuk mendapatkan informasi yang diinginkan. Karena belum ada konektivitas antar aplikasi.

Sedangkan untuk domain SDM, akar permasalahannya adalah kurangnya jumlah SDM dan kompetensi SDM yang kurang memadai. Dari data jumlah pejabat fungsional Pranata Komputer Kementerian Perhubungan, masing-masing unit eselon 1 masih kekurangan tenaga pegawai di bidang TI. Di lingkungan Kementerian Perhubungan hanya Pusdatin sebagai unit eselon II yang memiliki tugas pokok dan fungsi sebagai melaksanakan pembinaan dan pengembangan sistem informasi perhubungan, serta pelayanan data dan informasi perhubungan. Bersumber dari sik.dephub.go.id disebutkan total pegawai Kementerian Perhubungan 29.999 dan jumlah pegawai dengan jabatan fungsional pranata komputer adalah 43 orang. Selain hal tersebut, komposisi jumlah pegawai pranata komputer sangat kecil dibanding dengan keseluruhan jumlah pegawai. Permasalahan yang dihadapi oleh unit kerja baik di pusat maupun daerah dalam membuat kegiatan di bidang TI adalah kurangnya kompetensi SDM dalam menentukan kebutuhan dan spesifikasi teknis dari aplikasi maupun infrastruktur perangkat keras yang diusulkan, mengakibatkan implementasi dari kegiatan TI tidak sesuai dengan sasaran.

Dari penjelasan mengenai permasalahan utama mengenai silo system tersebut maka penulis tertarik untuk menyelesaikan salah satu domain permasalahan yaitu pada bagian domain infrastruktur dimana akar penyebabnya adalah belum adanya acuan atau kajian tentang perencanaan sistem informasi yang terintegrasi. Oleh karena itulah pada penelitian ini akan dilakukan tahapan awal dalam perencanaan strategis sistem informasi. Tahapan tersebut yaitu analisis As-Is dimana didalamnya akan memuat analisis kondisi bisnis dan juga kondisi sistem informasi/teknologi informasi saat ini.

Adapun ruang lingkup analisis As-Is Pada sistem informasi di Kementerian Perhubungan ini adalah:

1. Analisis kondisi bisnis saat ini, yaitu:

- Analisis internal bisnis meliputi aktivitas utama maupun pendukung khususnya pada Direktorat Jenderal Perhubungan Udara;

- Analisis eksternal bisnis organisasi;

- Analisis strength, weakness, opportunity dan threat untuk Kementerian Perhubungan;

2. Dilakukannya kondisi SI/TI saat ini, meliputi: Kondisi sistem informasi saat ini, kondisi infrastruktur TI saat ini, manajemen SI/TI dan analisis eksternal SI/TI.

\section{TINJAUAN PUSTAKa}

\subsection{Perencanaan Strategis Sistem Informasi}

Perencanaan strategis sistem informasi sangat bermanfaat untuk memenuhi tujuan jangka panjang bagi sebuah perusahaan maupun instansi [3]. Salah satu metode yang paling umum digunakan dalam perencanaan strategis system informasi yaitu metode Ward-Peppard. Pendekatan metode ini mengkombinasikan analisis kondisi bisnis dan kondisi SI/TI saat ini dan masa depan baik dari sisi internal maupun eksternal. Kondisi bisnis dan kondisi SI/TI saat ini atau lebih sering dikenal sebagai analisis As-Is diperlukan sebagai input untuk proses selanjutnya yaitu merumuskan strategi hingga akhirnya menjadi suatu roadmap [4]

\subsection{Analisis Value Chain}

Analisis value chain adalah mekanisme untuk melihat suatu organisasi sebagai rantai aktivitas yang memiliki nilai. Keunggulan kompetitif suatu organisasi ditentukan oleh efisiensi dalam mengelola biaya dan pengembangan perbedaan dari masing-masing kegiatan sebagai bentuk dari nilai-nilai organisasi yang diberikan ke konsumen [5]. Analisis rantai nilai memperlihatkan organisasi sebagai proses yang berkelanjutan dalam aktivitas penciptaan nilai. Analisis dilakukan dengan mempelajari potensi penciptaan nilai [6]

\subsection{Analisis PEST}

Analisis PEST mencakup kondisi lingkungan makro yaitu ekonomi, teknologi, polotik, dan sosial. Lingkungan ekonomi meliputi faktor-faktor yang memengaruhi daya beli dan pola membeli dari konsumen. Kemudian tekonologi menciptakan peluang dan pasar baru. Sedangkan politik mencakup undang-undang, 
kantor pemerintah, dan tekanan kolompok yang memengaruhi dan membatasi organisasi dan individu dalam masyarakat [7].

\subsection{Kuadran Mc Farlan}

Model pemetaan Mc Farlan bertujuan untuk menganalisis suatu sistem informasi di suatu sistem informasi di suatu organisasi berdasarkan kondisi saat ini, kondisi yang direncanakan, serta system informasi yang dianggap berpotensi dalam menunjang operasional dan strategi organisasi [4]. Kuadran dalam McFarlan dibagi menjadi empat kuadran yaitu strategic, high potential, key operational, dan support.

\section{Metode Penelitian}

Untuk lebih memudahkan dalam memetakan dan merencanakan perumusan strategi SI/TI di Kementerian Perhubungan maka metodologi disajikan dalam bentuk workflow seperti pada gambar 2 berikut ini:

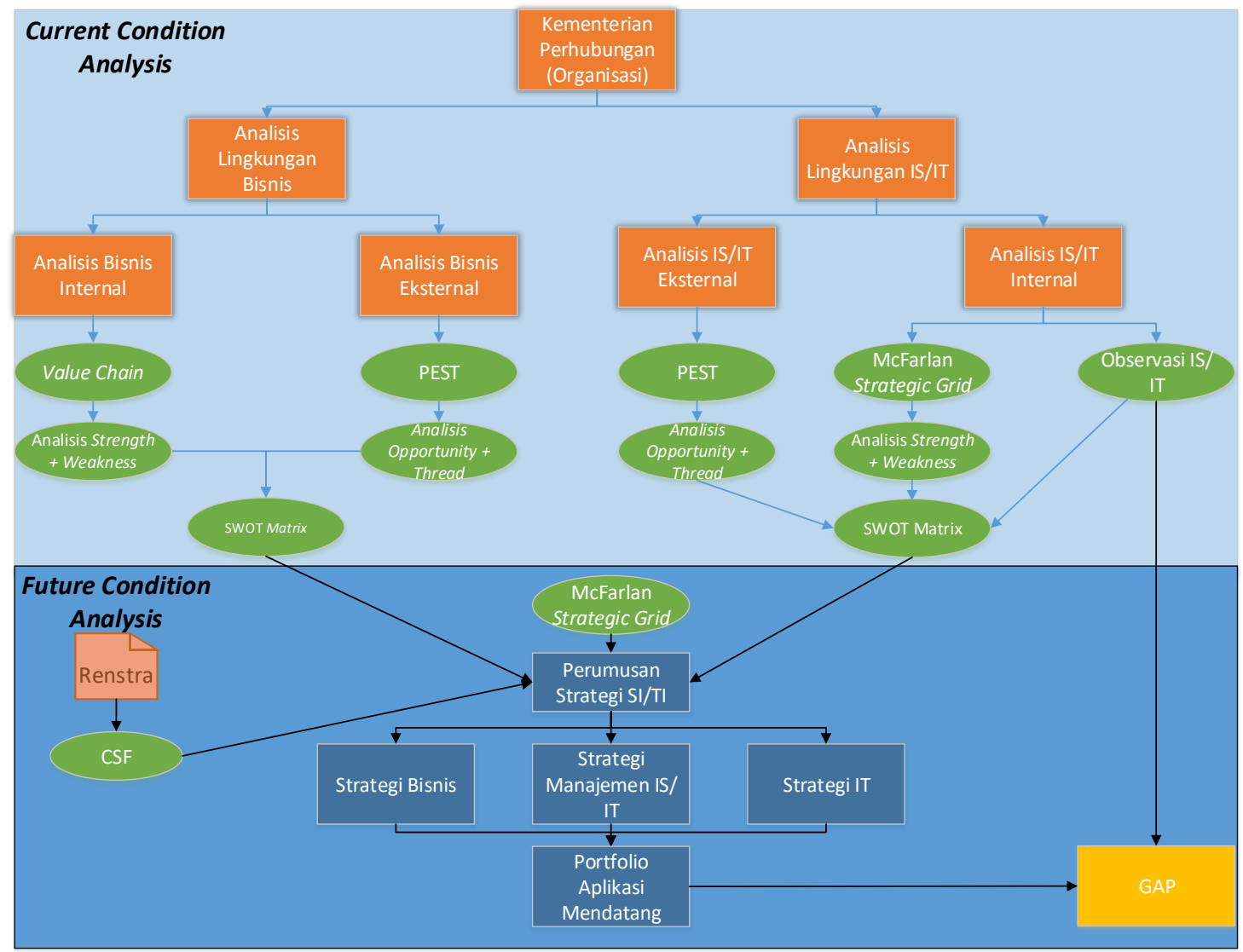

Gambar 2. Alur Perencanaan Strategis Sistem Informasi Keseluruhan

Dari gambar 2 dapat dilihat bahwa yang akan dilakukan pada penelitian ini terletak pada area atas yaitu current condition analysis atau analisis kondisi saat ini dimana terdiri dari 4 jenis yaitu analisis lingkungan bisnis internal, analisis lingkungan bisnis eksternal, analisis lingkungan SI/TI internal dan analisis lingkungan SI/TI eksternal. Kemudian output dari tahapan ini nantinya dapat digunakan dalam merumuskan strategi SI/TI dalam perencanaan strategis sistem informasi.

Beberapa teknik atau metode analisis yang digunakan adalah analisis value chain yang digunakan untuk memetakan proses bisnis, analisis SWOT dan kuadran Mc Farlan digunakan untuk memetakan kekuatan dan kelemahan sehingga dapat mengetahui kebutuhan organisasi. Kemudian analisis PEST digunakan untuk mengetahui ancaman dan kesempatan yang mungkin dapat diperhatikan organisasi dalam hal ini Kementerian Perhubungan. 
Dalam pelaksanaan penelitian ini metodologi yang digunakan dimulai dengan merumuskan permasalahan berkaitan dengan isu-isu strategis yang ada di Kementerian Perhubungan. Kemudian setelah itu dilakukan studi literatur berkaitan dengan metode dan tools yang akan digunakan dan cocok dengan konteks organisasi. Langkah selanjutnya adalah mengumpulkan data baik yang bersifat primer yaitu melakukan observasi dan wawancara langsung dengan pihak Pusdatin selaku pengelola kegiatan SI/TI di Kementerian Perhubungan dan mengumpulkan data-data sekunder yaitu dokumen rencana strategi dan dokumen lain seperti dokumen hasil reviu dari Pusdatin. Jika data dirasa sudah lengkap maka dilanjutkan dengan melakukan analisis terhadap kondisi bisnis dan SI/TI saat ini. Hasil analisis SWOT baik untuk kondisi bisnis maupun SI/TI kemudian dirangkum menjadi suatu kesimpulan dan saran bagi Kementerian Perhubungan untuk digunakan sebagai tahap selanjutnya dalam perencanaan strategis sistem informasi. Detail metodologi penelitian dapat dilihat pada gambar 3 berikut ini.

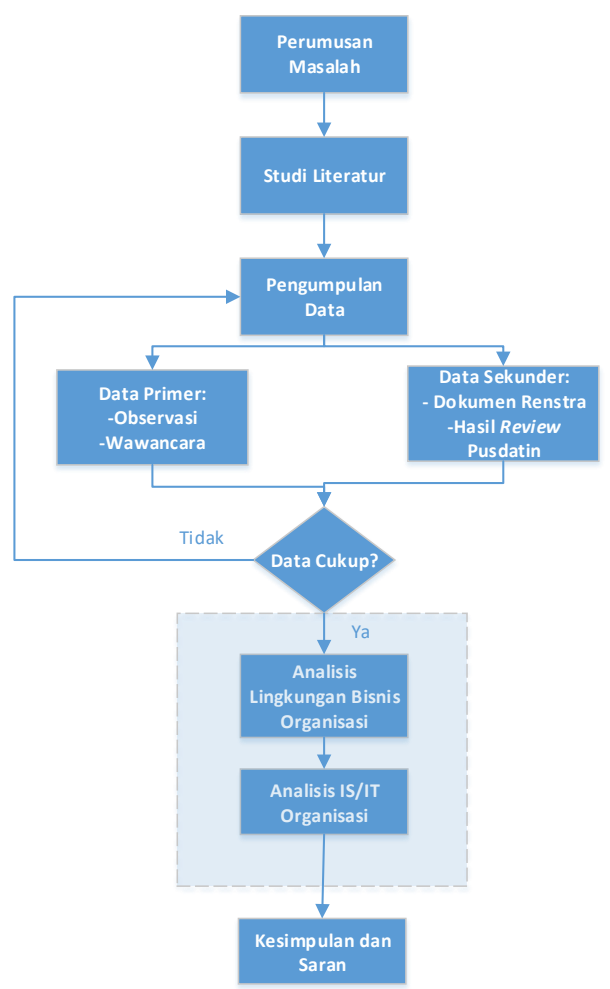

Gambar 3. Alur Perencanaan Strategis Sistem Informasi

\section{Hasil dan Pembahasan}

\subsection{Analisis Kondisi Bisnis Saat Ini}

Berdasarkan rencana strategis, Kementerian Perhubungan menjalankan serangkaian aktivitas-aktivitas yang mendukung proses bisnisnya. Tugas pokok Direktorat Jenderal Perhubungan Udara adalah merumuskan dan melaksanakan kebijakan dan standarisasi di bidang perhubungan udara. Untuk melaksanakan tugas pokok tersebut, Direktorat Jenderal Perhubungan Udara melaksanakan fungsi sebagai berikut:

1. Perumusan kebijakan Kementerian Perhubungan di bidang angkutan udara, keselamatan penerbangan, sertifikasi kelaikan udara, teknik bandar udara, fasilitas elektronika dan listrik penerbangan.

2. Pelaksanaan kebijakan di bidang angkutan udara, keselamatan penerbangan, sertifikasi kelaikan udara, teknik bandar udara, fasilitas elektronik dan listrik penerbangan.

3. Perumusan standar, norma, pedoman, kriteria dan prosedur di bidang perhubungan udara.

4. Pemberian bimbingan teknis dan evaluasi.

5. Pelaksanaan administrasi Direktorat Jenderal Perhubungan Udara, meliputi urusan tata usaha, kepegawaian dan rumah tangga Direktorat Jenderal. 
Berdasarkan tugas pokok dan fungsi diatas, model proses bisnis yang dilaksanakan Direktorat Jenderal Perhubungan Udara dapat dilihat pada gambar 4, berikut ini:

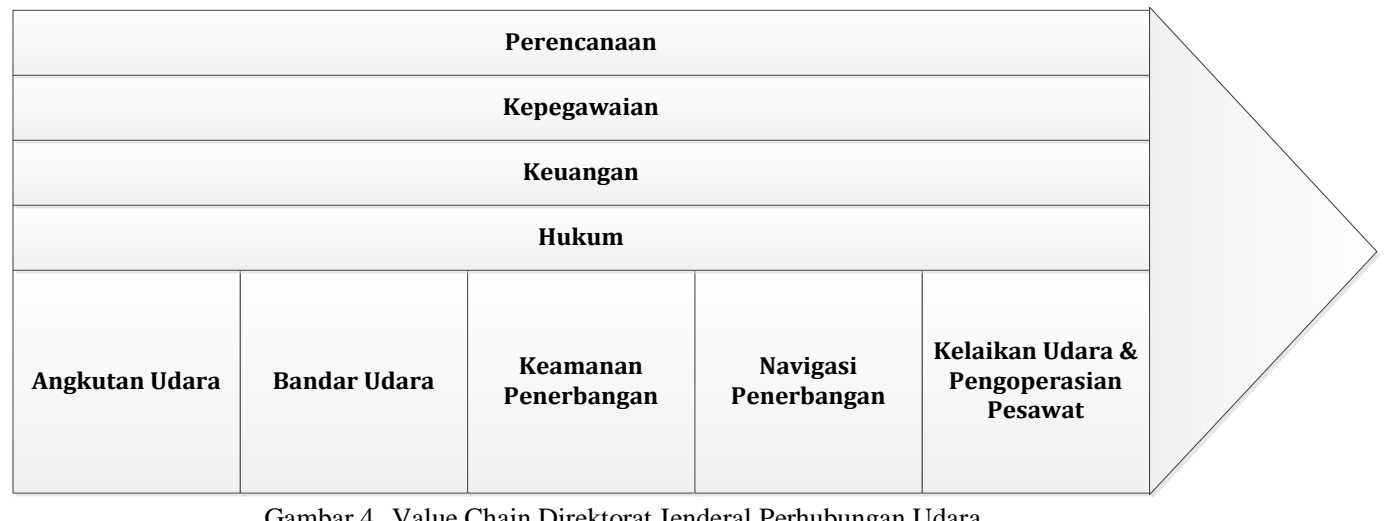

Gambar 4. Value Chain Direktorat Jenderal Perhubungan Udara

Berdasarkan aktivitas dalam proses bisnis yang sudah dijelaskan, maka dilakukan analisis untuk mengetahui kekuatan (strength) dan kelemahan (weakness) pada Direktorat Jenderal Perhubungan Udara. Berikut ini hasil analisis Strength-Weakness pada tabel 2 berdasarkan analisis value chain yang telah dilakukan.

Tabel 2 Analisis Strength-Weakness Lingkungan Bisnis

\begin{tabular}{|c|c|c|c|c|c|}
\hline \multirow{2}{*}{ Aktivitas } & \multirow{2}{*}{ Kondisi Saat ini } & \multicolumn{4}{|c|}{ Analisis } \\
\hline & & Standar/Regulasi & Kompetitor & $\begin{array}{c}\text { Expert } \\
\text { Judgement }\end{array}$ & $\mathrm{S} / \mathrm{W}$ \\
\hline \multicolumn{6}{|c|}{ Aktivitas Utama } \\
\hline $\begin{array}{l}\text { Perumusan } \\
\text { kebijakan }\end{array}$ & $\begin{array}{l}\text { Adanya kebijakan mengenai angkutan } \\
\text { udara, keselamatan penerbangan, sertifikasi } \\
\text { kelaikan, teknis, dan fasilitas penerbangan. }\end{array}$ & $\begin{array}{l}\text { PP No. } 3 \text { Tahun } 2001 \\
\text { mengenai Keamanan dan } \\
\text { Keselamatan Penerbangan }\end{array}$ & - & - & S \\
\hline $\begin{array}{l}\text { Pelaksanaan } \\
\text { kebijakan }\end{array}$ & $\begin{array}{l}\text { Adanya kebijakan mengenai angkutan } \\
\text { udara, keselamatan penerbangan, sertifikasi } \\
\text { kelaikan, teknis, dan fasilitas penerbangan. }\end{array}$ & $\begin{array}{l}\text { PP No. } 3 \text { Tahun } 2001 \\
\text { mengenai Keamanan dan } \\
\text { Keselamatan Penerbangan }\end{array}$ & - & - & $\mathrm{S}$ \\
\hline $\begin{array}{l}\text { Perumusan } \\
\text { standarisasi }\end{array}$ & $\begin{array}{l}\text { Adanya standarisasi norma, pedoman, } \\
\text { kriteria, dan prosedur di bidang } \\
\text { perhubungan udara. }\end{array}$ & $\begin{array}{l}\text { PP No. } 3 \text { Tahun } 2001 \\
\text { mengenai Keamanan dan } \\
\text { Keselamatan Penerbangan }\end{array}$ & - & - & $\mathrm{S}$ \\
\hline $\begin{array}{l}\text { Pemberian } \\
\text { bimbingan } \\
\text { teknis dan } \\
\text { evaluasi }\end{array}$ & $\begin{array}{l}\text { Adanya standar untuk bagian angkutan } \\
\text { udara, bandar udara, keamanan, navigasi, } \\
\text { dan kelaikan pengoperasian . }\end{array}$ & $\begin{array}{l}\text { PP No. } 3 \text { Tahun } 2001 \\
\text { mengenai Keamanan dan } \\
\text { Keselamatan Penerbangan }\end{array}$ & - & - & $\mathrm{S}$ \\
\hline \multicolumn{6}{|c|}{ Aktivitas Pendukung } \\
\hline $\begin{array}{r}\text { Pelaksanaan } \\
\text { administrasi }\end{array}$ & $\begin{array}{l}\text { Adanya kebijakan terkait Sekretariat } \\
\text { Direktorat Jenderal Perhubungan Udara. }\end{array}$ & $\begin{array}{l}\text { PP No. } 3 \text { Tahun } 2001 \\
\text { mengenai Keamanan dan } \\
\text { Keselamatan Penerbangan }\end{array}$ & - & - & $\mathrm{S}$ \\
\hline
\end{tabular}

Berdasarkan aktivitas dalam lingkungan eksternal bisnis Kementerian Perhubungan yang sudah dijelaskan, maka dilakukan analisis untuk mengetahui peluang (opportunity) dan ancaman (threat) pada Direktorat Jenderal Perhubungan Udara. Berikut ini pada tabel 3 hasil identifikasi Opportunity-Threat berdasarkan analisis eksternal yang telah dilakukan.

Tabel 3 Analisis Opportunity-Thread Lingkungan Bisnis

\begin{tabular}{|c|c|c|c|c|}
\hline $\begin{array}{c}\text { Kategori } \\
\text { Isu }\end{array}$ & Kondisi & $\begin{array}{c}\text { Dampak } \\
\text { Industri }\end{array}$ & Dampak Organisasi & O/T \\
\hline
\end{tabular}




\begin{tabular}{|c|c|c|c|c|}
\hline \multirow[t]{4}{*}{ Politik } & $\begin{array}{l}\text { Adanya PP Nomor } 77 \text { Tahun } 2012 \text { tentang } \\
\text { Perusahaan Umum (PERUM) Lembaga } \\
\text { Penyelenggara Pelayanan Navigasi } \\
\text { Penerbangan Indonesia }\end{array}$ & - & $\begin{array}{l}\text { Karyawan perusahaan pada unit layanan navigasi } \\
\text { dialihkan menjadi karyawan PERUM. }\end{array}$ & $\mathrm{T}$ \\
\hline & $\begin{array}{l}\text { Adanya PP No } 3 \text { Tahun } 2001 \text { tentang } \\
\text { Keamanan dan Keselamatan Penerbangan. }\end{array}$ & - & $\begin{array}{l}\text { Meningkatkan kinerja dalam menjamin keamanan } \\
\text { keselamatan penerbangan. }\end{array}$ & $\mathrm{O}$ \\
\hline & $\begin{array}{l}\text { Adanya Undang Undang No. } 14 \text { Tahun } 2008 \\
\text { tentang Keterbukaan Informasi Publik. }\end{array}$ & - & $\begin{array}{l}\text { Organisasi meningkatkan pembangunan infrastruktur, } \\
\text { karena meningkatnya permintaan data dan informasi } \\
\text { secara tidak wajar sehingga mengganggu kegiatan } \\
\text { utama. }\end{array}$ & $\mathrm{T}$ \\
\hline & $\begin{array}{l}\text { Adanya PP No } 81 \text { Tahun } 2010 \text { tentang } \\
\text { Grand Design Reformasi Birokrasi. }\end{array}$ & - & $\begin{array}{l}\text { Reorganisasi untuk dapat melaksanakan peran dan } \\
\text { fungsi birokrasi secara tepat, cepat dan konsisten. }\end{array}$ & $\mathrm{O}$ \\
\hline \multirow[t]{2}{*}{ Ekonomi } & Adanya Pinjaman dan hibah dari luar negeri. & - & $\begin{array}{l}\text { Keuangan Direktorat Jenderal Perhubungan terbantu } \\
\text { dalam menjalankan tugasnya. }\end{array}$ & $\mathrm{O}$ \\
\hline & $\begin{array}{l}\text { Tahun } 2020 \text { liberalisasi perdagangan dan } \\
\text { jasa berlaku penuh di wilayah Asia Pasifik. }\end{array}$ & & $\begin{array}{l}\text { Meningkatnya kegiatan pembangunan infrastruktur } \\
\text { transportasi }\end{array}$ & $\mathrm{O}$ \\
\hline Sosial & $\begin{array}{l}\text { Kepercayaan masyarakat dengan pelayanan } \\
\text { penerbangan udara yang cepat. }\end{array}$ & - & Menjaga komitmen kecepatan kinerja pegawai. & $\mathrm{O}$ \\
\hline Teknologi & $\begin{array}{l}\text { Perkembanganan teknologi informasi yang } \\
\text { sangat cepat. }\end{array}$ & - & $\begin{array}{l}\text { Mengadopsi dan menerapkan teknologi informasi } \\
\text { untuk mendukung kegiatan utama dan pendukungnya. }\end{array}$ & $\mathrm{O}$ \\
\hline
\end{tabular}

\subsection{Analisis Kondisi SI/TI Saat Ini}

Beberapa aplikasi yang telah berjalan dan digunakan spesifik untuk Ditjen Perhubungan Udara saat ini adalah seperti pada tabel 4 berikut ini.

Tabel 4 Analisis Opportunity-Thread Lingkungan Bisnis

\begin{tabular}{|c|l|l|l|}
\hline No. & \multicolumn{1}{|c|}{ Aplikasi } & \multicolumn{1}{|c|}{ Deskripsi } & \multicolumn{1}{c|}{ Permasalahan } \\
\hline $\mathbf{1}$ & Aplikasi Pass Bandara & $\begin{array}{l}\text { Aplikasi ini digunakan untuk } \\
\text { membuat Pass Bandara. }\end{array}$ & $\begin{array}{l}\text { Setiap kantor Otoritas Bandara mengembangkan } \\
\text { sendiri aplikasi sistem Pass Bandara, sehingga } \\
\text { dibutuhkan standarisasi pass bandara. }\end{array}$ \\
\hline $\mathbf{2}$ & $\begin{array}{l}\text { Sistem Manajemen Dokumen dan } \\
\text { Tata Persuratan Dinas } \\
\text { Perhubungan Udara. }\end{array}$ & $\begin{array}{l}\text { Suatu sistem pengelolaan } \\
\text { naskah dinas yang dibangun } \\
\text { dengan memanfaatkan TIK } \\
\text { yang bersifat legal. }\end{array}$ & $\begin{array}{l}\text { Sistem ini belum sepenuhnya berjalan di semua } \\
\text { Direktorat Jenderal di kantor pusat karena adanya } \\
\text { perbedaan penomoran dan hal-hal terkait administrasi } \\
\text { di masing-masing Direktorat Jenderal (Eselon I). }\end{array}$ \\
\hline
\end{tabular}

Berdasarkan daftar aplikasi yang dimiliki oleh Kementerian Perhubungan maka aplikasi-aplikasi tersebut dapat dipetakan ke dalam kuadran McFarlan seperti pada gambar 5. Model pemetaan McFarlan bertujuan untuk menganalisis suatu aplikasi atau sistem informasi di suatu organisasi berdasarkan kondisi saat ini, kondisi yang direncanakan serta aplikasi-aplikasi yang dianggap berpotensi dalam menunjang operasional dan strategi organisasi.

Berdasarkan analisis dampak aplikasi terhadap proses bisnis organisasi maka dapat dilihat bahwa aplikasi yang dimiliki Kementerian Perhubungan dibagi menjadi beberapa kuadran yaitu sebagai berikut:

a. Support

Aplikasi yang termasuk dalam kuadran ini adalah aplikasi yang memberikan dukungan terhadap proses bisnis tetapi bukan hal yang kritis karena tanpa adanya aplikasi ini, organisasi tetap dapat melakukan proses bisnisnya menggunakan cara konvensional atau manual. Aplikasi yang masuk dalam kuadran ini adalah sistem manajemen dokumen dan tata persuratan serta sistem informasi kepegawaian.

b. Key Operational

Aplikasi yang dikelompokkan dalam kuadran ini adalah aplikasi yang memberikan dampak positif terhadap proses bisnis organisasi dan merupakan aplikasi yang kritis. Artinya jika tidak ada aplikasi tersebut maka proses bisnis menjadi terganggu dan bahkan tidak dapat berjalan. Aplikasi yang masuk dalam kuadran ini adalah Portal Kementerian Perhubungan, LPSE Kementerian Perhubungan, SIASATI, JDIH, Sistem E-Monitoring, dan Sistem informasi Pass Bandara. 


\section{c. Strategic}

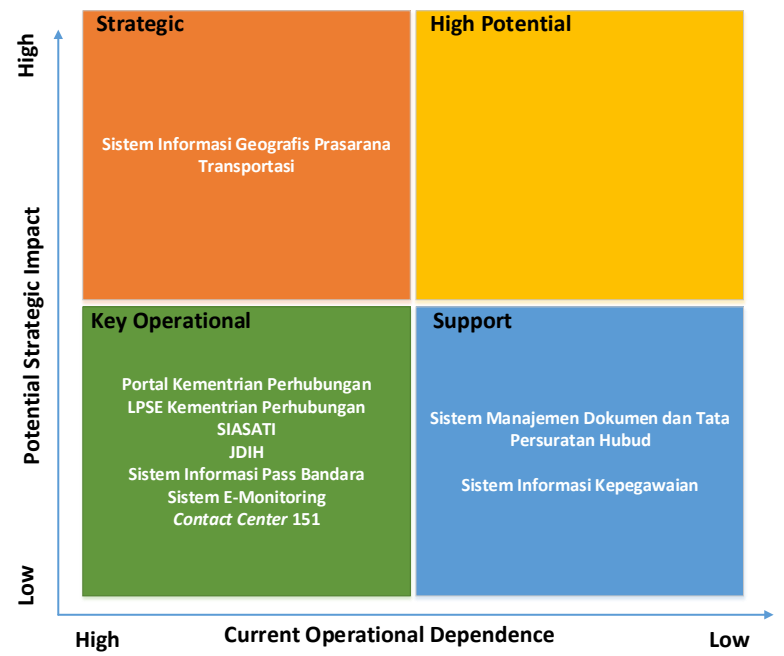

Gambar 5. Pemetaan Sistem Informasi Dirjen Hubud dalam Kuadran McFarlan

Aplikasi yang termasuk dalam kuadran ini adalah aplikasi yang selain memberikan dampak positif terhadap proses bisnis organisasi dan kritis namun juga untuk kedepannya memberikan keuntungan kompetitif yang sifatnya berkelanjutan. Aplikasi di Kementerian Perhubungan yang masuk ke dalam kriteria ini adalah contact center 151 yang secara terus menerus dapat memberikan saran dan menampung aspirasi yang dapat meningkatkan layanan kepada masyarakat. Selain itu, aplikasi GIS juga termasuk ke kuadran ini karena dapat menyajikan data prasarana perhubungan berbentuk tabular seperti data terminal, bandara dan pelabuhan serta data-data statistik secara online terkait prasarana transportasi dan beberapa data pendukung terkait. Data tersebut digunakan untuk pengambilan kebijakan dalam level strategis sehingga berdampak pada masyarakat kedepannya secara berkelanjutan.

Kemudian untuk mendukung rencana strategis dari Kementerian Perhubungan, maka fasilitas SI/TI yang dimiliki oleh Kementerian Perhubungan memegang peranan yang penting. Pusdatin sebagai unit kerja yang memiliki tugas pokok dan fungsi pengelolaan sumber daya Teknologi Informasi dan Komunikasi (TIK) di lingkungan Kementerian Perhubungan sebagaimana telah diamanatkan pada KEPMEN Nomor 60 tahun 2011 selalu berupaya melakukan pembenahan dalam pengelolaan SI/TI. Berikut ini adalah kondisi terperinci infrastruktur TI saat ini yang sudah dikembangkan dan digunakan oleh Kementerian Perhubungan. 


\section{LAYANAN}
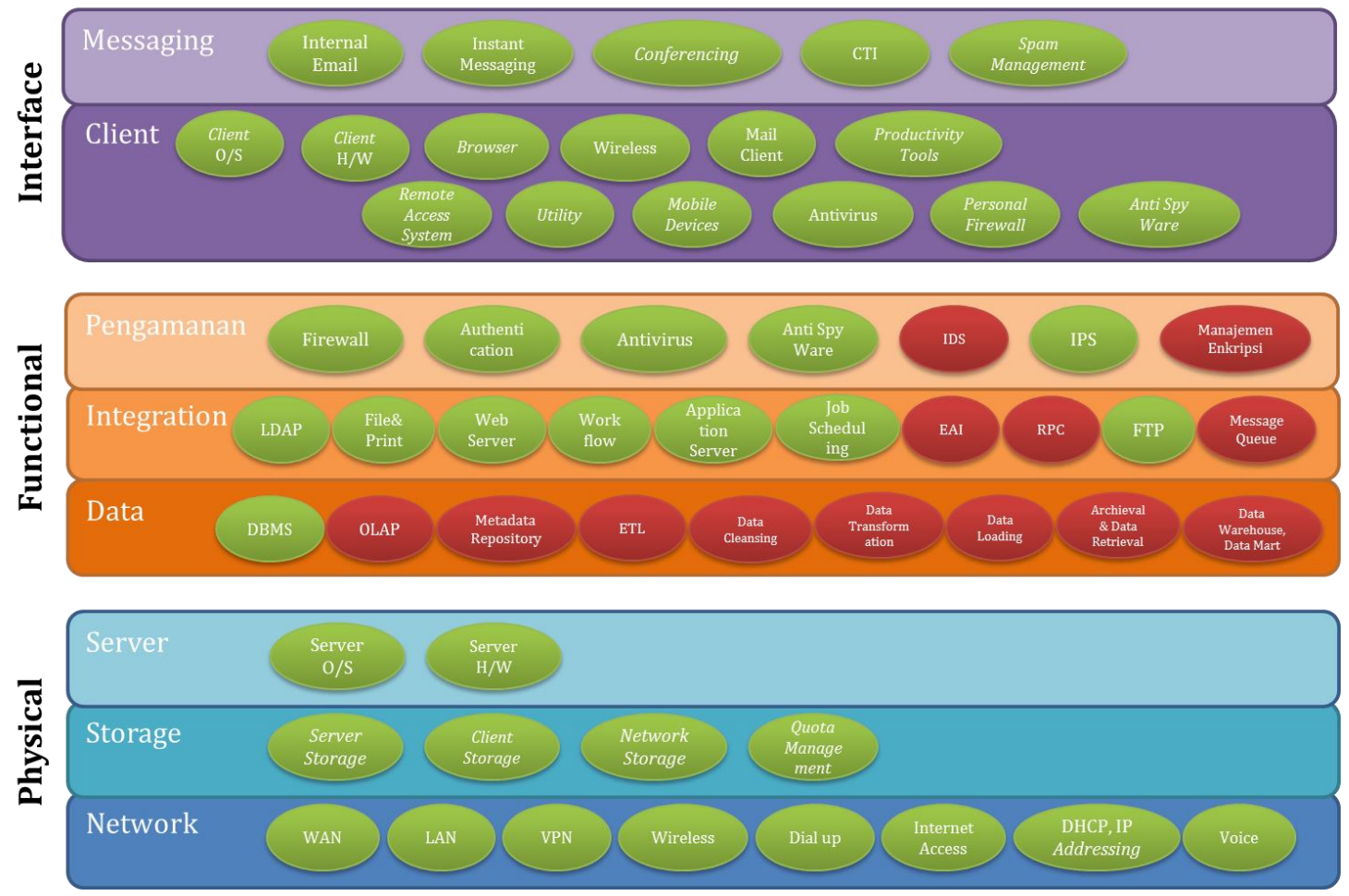

Gambar 6. Daftar Layanan Infrastruktur Dirjen Hubud Kementerian Perhubungan. Keterangan: Hijau: Ada, Merah: Tidak Ada

Infrastruktur TI di Direktorat Direktorat Perhubungan Udara memiliki beberapa permasalahan. Permasalahan tersebut dijelaskan seperti berikut:

1. Keberadaan server tidak terpusat

Direktorat Perhubungan Udara telah memiliki jaringan berupa LAN dan koneksi internet serta memiliki server layanan yang terhubung dengan workstations. Namun, keberadaan server tersebut tidak dikelola oleh Pusdatin. Hal tersebut tidak sesuai KP. 39 Tahun 2009 pasal 6 dan 7 yang menjelaskan bahwa Direktorat Jenderal serta Badan-Badan harus berkoordinasi dengan Pusdatin sebagai penanggung jawab penyelenggara TIK di Lingkungan Kementerian Perhubungan sehingga pembangunan maupun pengembangan TIK di lingkungan Kementerian Perhubungan dapat dilaksanakan secara terpusat.

2. Belum ada pengelolaan data center

Pengelolaan data center khusus untuk Direktorat Perhubungan Udara oleh Pusdatin belum dilakukan.

3. Belum ada pemetaan jaringan dengan pihak eksternal

Berdasarkan topologi jaringan yang digunakan saat ini, maka dapat dilihat bahwa belum ada pemetaan hubungan dengan pihak eksternal sehingga belum menunjang distribusi informasi yang efektif dan efisien. Berikut pada gambar 7 adalah topologi jaringan yang digunakan di Direktorat Perhubungan Udara saat ini: 


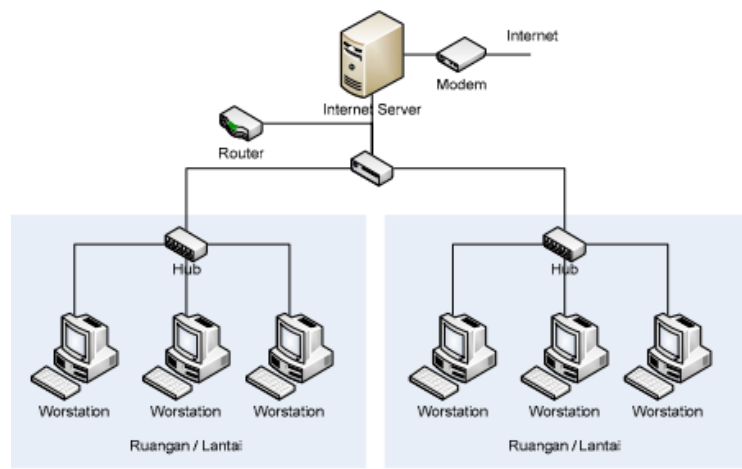

Gambar 7 Topologi Jaringan Ditjen Perhubungan Udara

Untuk mewujudkan distribusi informasi yang efektif dan efisien, maka dibutuhkan akses dan koneksi data serta tingkat keamanan informasi yang tinggi dan juga peningkatan quality of service (QoS).

4. Belum ada layering untuk integrasi jaringan

Dari sisi segregasi jaringan, layering diperlukan untuk memetakan lapisan distribution, access dan core untuk kebutuhan integrasi lebih lanjut. Integrasi dengan subnet server membutuhkan topologi untuk mendukung manajemen yang tepat.

5. Belum ada standarisasi perangkat jaringan

Infrastruktur TI di Direktorat Perhubungan Udara seperti perangkat, keamanan dan arsitektur jaringan belum memiliki standarisasi yang mendukung integrasi layanan-layanan aplikasi yang ada di Direktorat Perhubungan Udara.

6. Belum ada standarisasi keamanan informasi

Standarisasi keamanan informasi belum dipenuhi oleh Ditjen Perhubungan Udara untuk mendukung integrasi di lapisan sistem informasi.

Setelah dilakukan identifikasi permasalahan terhadap kondisi infrastruktur, kemudian data-data tersebut dianalisis menggunakan analisis strength-weakness seperti pada tabel 5.

Tabel 5 Analisis kekuatan dan kelemahan dari kondisi internal SI/TI di Kementerian Perhubungan.

\begin{tabular}{|c|c|c|c|c|c|}
\hline \multirow[t]{2}{*}{ No } & \multirow[t]{2}{*}{ Kondisi Internal } & \multicolumn{3}{|c|}{ Analysis } & \multirow[t]{2}{*}{$\mathbf{S} / \mathbf{W}$} \\
\hline & & Standard & Competitor & Expert Opinion & \\
\hline 1 & $\begin{array}{l}\text { Server aplikasi dan database di } \\
\text { Kemenhub mayoritas masih berada di } \\
\text { masing- masing direktorat. }\end{array}$ & $\begin{array}{l}\text { Service Oriented Architecture } \\
\text { (SOA) dan pasal } 6 \text { dan } 7 \text { KP. } 39 \\
\text { Tahun } 2009 .\end{array}$ & & & W \\
\hline 2 & $\begin{array}{l}\text { Ketersedianya } \\
\text { jaringan lintas sektor yang } \\
\text { menghubungkan kantor pusat dengan } \\
\text { sektor maupun subsektor dibawahnya } \\
\text { di daerah dengan menggunakan } \\
\text { teknologi VPN. }\end{array}$ & $\begin{array}{l}\text { Standardisasi, kompatibel dengan } \\
\text { standar protokol Internet } \\
\text { Engineering Task Force (IETF) } \\
\text { dan } \\
\text { vendor dunia lainnya. }\end{array}$ & & & $\mathrm{S}$ \\
\hline 3 & $\begin{array}{l}\text { Aplikasi yang ada belum bersifat } \\
\text { multi platform. }\end{array}$ & $\begin{array}{l}\text { Open Standard } \\
\text { sistem informasi dan } \\
\text { infrastruktur TI. }\end{array}$ & & & $\mathrm{W}$ \\
\hline 4 & $\begin{array}{l}\text { Sudah mengadopsi } \\
\text { teknologi jaringan } \\
\text { berbasiskan protocol TCP/IP, Internet } \\
\text { Proxy, DHCP dan VOIP. }\end{array}$ & $\begin{array}{l}\text { Standar protokol } \\
\text { jaringan OSI Layer, TCP/IP dan } \\
\text { IPv4. }\end{array}$ & & & S \\
\hline 5 & $\begin{array}{l}\text { Adanya kebijakan yang berkaitan } \\
\text { dengan pengaturan dan pemanfaatan } \\
\text { teknologi informasi secara } \\
\text { menyeluruh di lingkungan } \\
\text { Kementerian Perhubungan sesuai } \\
\text { pasal } 6 \text { dan } 7 \text { KP. } 39 \text { Tahun } 2009 \text {. }\end{array}$ & & & $\begin{array}{l}\text { Lynda M } \\
\text { Applegate, Robert } \\
\text { D.Austin, dan } \\
\text { Deborah L } \\
\text { Soule dalam } \\
\text { teori IT } \\
\text { Governance.[8] }\end{array}$ & $\mathrm{S}$ \\
\hline
\end{tabular}




\begin{tabular}{|c|c|c|c|c|c|}
\hline \multirow[t]{2}{*}{ No } & \multirow[t]{2}{*}{ Kondisi Internal } & \multicolumn{3}{|c|}{ Analysis } & \multirow[t]{2}{*}{$S / W$} \\
\hline & & Standard & Competitor & Expert Opinion & \\
\hline 6 & $\begin{array}{l}\text { Sudah ada biro khusus yang } \\
\text { menangani teknologi informasi } \\
\text { yaitu Pusdatin. }\end{array}$ & & & $\begin{array}{l}\text { Lynda M } \\
\text { Applegate, } \\
\text { Robert } \\
\text { D.Austin, dan } \\
\text { Deborah L } \\
\text { Soule dalam } \\
\text { teori IT } \\
\text { Governance }[8]\end{array}$ & $\mathrm{S}$ \\
\hline 7 & $\begin{array}{l}\text { Aplikasi belum } \\
\text { terintegrasi. }\end{array}$ & $\begin{array}{l}\text { Service Oriented Architecture } \\
\text { (SOA) }\end{array}$ & & & W \\
\hline 8 & $\begin{array}{l}\text { Belum ada pengaturan standar } \\
\text { keamanan dalam } \\
\text { organisasi. }\end{array}$ & ISO 27001 & & & $\mathrm{~W}$ \\
\hline 9 & $\begin{array}{l}\text { Belum adanya kegiatan pelatihan } \\
\text { karyawan untuk meningkatkan } \\
\text { kompetensi dan pemahaman TI. }\end{array}$ & $\begin{array}{l}\text { ISO 9001:2000 (6.2.2 } \\
\text { Kompetensi, Kesadaran dan } \\
\text { Training) } \\
\text { Menyediakan Pelatihan } \\
\text { Mengevaluasi efektifitas } \\
\text { pelatihan }\end{array}$ & & & $\mathrm{W}$ \\
\hline 10 & $\begin{array}{l}\text { Belum adanya pengukuran kinerja } \\
\text { karyawan TI secara } \\
\text { jelas. }\end{array}$ & $\begin{array}{l}\text { ISO 9001:2000 6.1 Ketersediaan } \\
\text { Sumber Daya } \\
\text { Organisasi harus menentukan dan } \\
\text { menyediakan sumber daya yang } \\
\text { dibutuhkan } \\
\text { koreksi dan pencegahan. }\end{array}$ & & & W \\
\hline 11 & $\begin{array}{l}\text { Aplikasi mayoritas masih bersifat Key } \\
\text { Operational. }\end{array}$ & & & $\begin{array}{l}\text { Investasi dalam bidang TI } \\
\text { harus dijadikan sebagai } \\
\text { sebuah peluang yang } \\
\text { memberikan nilai tambah } \\
\text { saat ini maupun yang akan } \\
\text { datang [8] }\end{array}$ & $\mathrm{W}$ \\
\hline
\end{tabular}

Sedangkan untuk analisis PEST terhadap kondisi SI/TI saat ini menghasilkan opportunity (peluang) dan threat (ancaman) terhadap organisasi..

a. Peluang

1. Diharapkan dapat tercapai sistem yang terintegrasi, efisien, dan tepat sasaran di Kementerian Perhubungan.

2. Tidak diperlukan perubahan SI/TI secara signifikan untuk menyesuaikan proses bisnis.

3. Komputasi data yang dilakukan oleh Kementerian Perhubungan dapat dilakukan dengan cepat.

4. Adanya manajemen pengaturan bandwidth agar jaringan dapat digunakan dengan optimal.

b. Ancaman

1. Keputusan-keputusan strategis TIK diambil secara terfragmentasi oleh Pusdatin dan/atau tiap Direktorat Jenderal/Setara.

2. Adanya aplikasi yang bersifat proprietary menyebabkan jika tidak dialokasikan ke dalam anggaran maka patch aplikasi juga menjadi terlambat diterima.

3. Mekanisme backup dan recovery sistem tidak berjalan dengan baik.

4. Biaya tinggi untuk investasi video conference dan jaringan wireless 


\section{Kesimpulan}

Berdasarkan hasil penelitian yang telah dilakukan, maka dapat disimpulkan hal-hal sebagai berikut:

1. Pada lingkungan bisnis, Direktorat Jenderal Perhubungan Udara telah memiliki standar dan acuan yang dapat digunakan sebagai pedoman pada kegiatan/aktivitas utama dan pendukungnya sehingga menjadi kekuatan (Strength). Namun perlu dirumuskan suatu strategi untuk mengatasi ancaman yang mungkin terjadi yaitu Adanya PP Nomor 77 Tahun 2012 tentang Perusahaan Umum (PERUM) Lembaga Penyelenggara Pelayanan Navigasi Penerbangan Indonesia dan Adanya Undang Undang No. 14 Tahun 2008 tentang Keterbukaan Informasi Publik.

2. Pada lingkungan SI/TI masih banyak permasalahan yang harus diperhatikan oleh Dirjen Hubud sehingga menjadi kelemahan. Permasalahan tersebut antara lain yaitu:

a. Server aplikasi dan database di Kemenhub mayoritas masih berada di masing- masing direktorat.

b.Aplikasi yang ada belum bersifat multi platform.

c. Aplikasi belum terintegrasi.

d.Belum ada pengaturan standar keamanan dalam organisasi.

e. Belum adanya pengukuran kinerja karyawan TI secara jelas.

f. Belum adanya kegiatan pelatihan karyawan untuk meningkatkan kompetensi dan pemahaman TI. g.Aplikasi mayoritas masih bersifat Key Operational.

Ketujuh permasalahan yang sekaligus menjadi kelemahan tersebut selanjutnya harus dipetakan ke dalam ranah solusi dalam perencanaan strategis system informasi sehingga dapat dimanfaatkan untuk merumuskan strategi dan rekomendasi hingga roadmap selama lima tahun ke depan.

\section{Daftar Pustaka}

[1] K. Perhubungan, "Dephub," 2014. .

[2] Pusdatin, "Reviu Kegiatan TIK di Lingkungan Kementerian Perhubungan,” Jakarta, 2015.

[3] S. Alamri, N. Alutiri, H. Ballahmar, and A. Zafaar, "Strategic Information System Planning: A Case Study of a Service Delivery Company," Int. Adv. Res. J. Sci. Eng. Technol., vol. 3, no. 5, pp. 78-84, 2016.

[4] J. Ward and J. Peppard, Strategic Planning for Information Systems. 2002.

[5] G. Rifai, Prinsip - Prinsip Pengelolaan Strategi Bisnis. Jakarta: PT Gramedia Pustaka Utama, 2012.

[6] N. D. Retnowati, "Analisis Lingkungan Internal dan Eksternal Studi Kasus: PT Intan Pariwara Klaten," J. Buana Inform., vol. 1, no. 2, pp. 91-96, 2010.

[7] G. G. Dess, G. T. T. Lumpkin, and M. L. Taylor, Strategic Management: Creating Competitive Advantages. McGraw-Hill Education. Mc Graww-Hill Education, 2004.

[8] L. Applegate, R. Austin, and D. Soule, Corporate Information Strategy and Management: Text and Cases. McGraw-Hill/Irwin, 2009. 